\section{Effect of nanoparticles suspension on the growth of mung (Vigna radiata) seedlings by foliar spray method}

\author{
Shailesh K. Dhoke, ${ }^{1}$ Pramod Mahajan, \\ Rajashri Kamble, ${ }^{2}$ Anand Khanna ${ }^{1}$ \\ 'Department of Metallurgical Engineering \\ and Material Science, Indian Institute of \\ Technology Bombay, India; ' Department \\ of Microbiology, Shivaji University, \\ Kolhapur, India
}

\section{Abstract}

The present experimental investigation demonstrates the effect of nano-ZnO, nano$\mathrm{FeO}$ and nano-ZnCuFe-oxide particles on the growth of mung (Vigna radiata) seedling. The study was carried out by spraying optimum concentrations of nanoparticles in suspension form on hydroponically grown test units and examining the effect on the shoot growth of seedlings. Based on biomass assay, it was found that the seedlings displayed good growth over control, demonstrating a positive effect of the nanoparticle treatment. The best performance was observed for nano-ZnCuFe-Oxide followed by nano-FeO and nano-ZnO. Absorption of nanoparticles by plant leaves was also detected by inductive coupled plasma/atomic emission spectroscopy.

\section{Introduction}

Agriculture forms the backbone of third world economics. The increase of population and demand results in the need for great efficient agriculture products. However, changing environmental conditions are affecting the agriculture production. The development in agriculture system of any country is a point of concern to suit the need. Nanotechnology is an emerging technology and promises to substantially help agriculture, which can lead to a new revolution. ${ }^{1}$ Nanotechnology has been found to solve many of the agriculture-related problems with tremendous improvement, as compared to conventional agriculture systems. The use of nanoparticles in the growth of plants and for the control of plant diseases is a recent practice. ${ }^{1-7}$ However, the issue of whether plant growth is beneficial or harmful remains unresolved. ${ }^{8-10}$ Various studies were carried out to understand the effect of nanoparticles on the growth of plants. For example, Lu et al. ${ }^{11}$ studied the effect of mixtures of nano- $\mathrm{SiO}_{2}$ and nano- $\mathrm{TiO}_{2}$ on soybean seed. They found that the mixture of nanoparticles increases nitrate reductase in soybean, increasing its germination and growth. Hong et al..$^{12,13}$ and Yang et $a l .{ }^{14}$ reported that a proper concentration of nano- $\mathrm{TiO}_{2}$ was found to improve the growth of spinach by promoting photosynthesis and nitrogen metabolism. Canas et al. ${ }^{15}$ found that nanofunctionalized carbon nanotubes enhanced root elongation in onion and cucumber. Globally, many countries have identified the potential of nanotechnology in the agriculture sector and are trying to explore it significantly through research and development.

The present study deals with the effect of nano-ZnO, nano-FeO and nano-ZnCuFe-Oxide particle suspension as micro-nutrient on the growth of mung (Vigna radiata) seedlings by foliar spray method. Foliar spray method is more practical from an agronomic standpoint as plant can absorb essential elements through their leaves more efficiently compared to root feeding.

\section{Materials and Methods}

\section{Preparation of nanoparticle suspension}

Nano-Zn0 (particle size: $20 \mathrm{~nm}$ ), nano$\mathrm{FeO}$ (particle size: $100 \mathrm{~nm}$ ), and nano-ZnFeCu0xide (particle size: $20-40 \mathrm{~nm}$ ) were used for this study. The nanoparticles with concentration 20 ppm nano-ZnO, 50 ppm Nano-FeO, and $50 \mathrm{ppm}$ nano- $\mathrm{ZnFeCu}-0 x i d e$ by weight were directly suspended in deionized water and were dispersed by using mechanical stirrer and ultrasonicator ( $100 \mathrm{~W}, 40 \mathrm{khz}$ ) for $30 \mathrm{~min}$. The concentration of nanoparticles was fixed based on a preliminary study carried out using Hoagland solution and those concentrations which showed maximum effect were selected for foliar spray method.

\section{Seeds}

Seeds of plant species mung (Vigna radia$t a$ ) were purchased locally. Seeds were kept in a dry place in the dark under room temperature prior to use.

\section{Germination of mung seeds and hydroponic culture}

Mung seed used for this study were sterilized in 5\% sodium hypochlorite solution for 10 min to ensure surface sterility and were rinsed thoroughly with deionized water several times. Mung seeds were allowed to germinate in deionized water for $2 \mathrm{~h}$. The seeds were checked for germination, and seeds that had sprouted were used for test. The sprouted seeds were transferred to Petri dishes for growth up to three days. Each Petri dish contained $30 \mathrm{~mL}$ culture media (2.5\% agar) were used. For prepar-
Correspondence: Shailesh K. Dhoke, Department of Metallurgical Engineering and Material Science, Indian Institute of Technology Bombay, Mumbai, Powai-400076, India.

Tel. +91.22.25767891 - Fax: +91.22 .25723480 .

E-mail: shailesh_zeo@rediffmail.com

Key words: nanoparticles, mung seedlings, foliar spray.

Acknowledgments: the authors acknowledge the Indian Council of Agriculture Research (ICAR) for the financial support under the National Agricultural Innovative Project (NAIP), and the Indian Institute of Technology Bombay for providing analytical characterization techniques. The authors also acknowledge Ms. Rajashri Dilip Kamble, research student at the Department of Microbiology, Shivaji University, Kolhapur, MS, India, for her technical help in writing this article.

Contributions: ASK, principal investigation and project leading; SKD, data analysis and interpretation; PM, experiments conduction and data collection; RK, manuscript writing and literature survey.

Conflict of interests: the authors declare no potential conflict of interests.

Funding: the work was funded by the Indian Council of Agriculture Research (ICAR) under the National Agricultural Innovative Project (NAIP).

Received for publication: 7 September 2012. Accepted for publication: 22 January 2013.

This work is licensed under a Creative Commons Attribution NonCommercial 3.0 License (CC BYNC 3.0).

@CCopyright S.K. Dhoke et al., 2013

Licensee PAGEPress, Italy

Nanotechnology Development 2013; 3:e1 doi:10.4081/nd.2013.e1

ing the agar Petri dishes, $30 \mathrm{~mL}$ of $2.5 \%$ agar solution were poured into Petri dishes and immediately hardened in freezer. For each Petri dish, 10 plant seedlings were just placed above the surface of the agar media. The Petri dishes were placed in an incubator at a controlled temperature of $25 \pm 1^{\circ} \mathrm{C}$ in the dark. For three days, after the 3-day-incubation period, the seedlings were separated from the agar media washed with distilled water and the seedlings of equal length were transferred to polyethylene pots (containing $130 \mathrm{~mL}$ Hoagland solution). In the control, the whole nutrient solution was added, while in the case of nanoparticles treated plants, the respective lack of nutrients solution that was sprayed by sprayer. The composition of nutrient solution (1 strength Hoagland solution) were $20 \mathrm{ppm}\left(\mathrm{NH}_{4}\right)_{2} \mathrm{SO}_{4}, 10 \mathrm{ppm} \mathrm{NH}_{4} \mathrm{NO}_{3}$, $3.1 \mathrm{ppm} \mathrm{NaH}_{2} \mathrm{PO}_{4}, 40$ ppm $\mathrm{K}_{2} \mathrm{SO}_{4}, 15 \mathrm{ppm}$ $\mathrm{CaCl}_{2} \cdot 2 \mathrm{H}_{2} \mathrm{O}, 0.35$ ppm EDTA-FeNa. $3 \mathrm{H}_{2} \mathrm{O}, 25 \mathrm{ppm}$ $\mathrm{MgSO}_{4} \cdot 3 \mathrm{H}_{2} \mathrm{O}, 20 \mathrm{ppm} \mathrm{Al}{ }_{2}\left(\mathrm{SO}_{4}\right)_{3} \cdot 18 \mathrm{H}_{2} \mathrm{O}, 0.1 \mathrm{ppm}$ 
$\mathrm{ZnSO}_{4} .7 \mathrm{H}_{2} \mathrm{O}, \quad 0.1 \mathrm{ppm} \quad \mathrm{H}_{3} \mathrm{BO}_{3}, \quad 0.025 \mathrm{ppm}$ $\mathrm{CuSO}_{4} \cdot 5 \mathrm{H}_{2} \mathrm{O}, 1 \mathrm{ppm} \mathrm{MnSO}_{4} \cdot \mathrm{H}_{2} \mathrm{O}$ and $0.05 \mathrm{ppm}$ $\mathrm{Na}_{2} \mathrm{MO}_{4} \cdot 2 \mathrm{H}_{2} \mathrm{O}$. The $\mathrm{pH}$ of the nutrient solution was adjusted to 6.8 . The pots were kept in growth chamber under controlled condition (light condition of $100 \mathrm{mMol} \mathrm{m}{ }^{2} \mathrm{~s}^{1}, 10 \mathrm{~h}$ light/14 h dark cycle at $28^{\circ} \mathrm{C}$ ) for further growth. For each test, six replicates were prepared. The spreading suspension of nanoparticles and adding of Hoagland solution was carried out every two days to get nutrient and maintain $\mathrm{pH}$. The experiment was carried out for 12 days.

\section{Biomass assay}

For biomass analysis, the plant were harvested after 12 days. The root and shoot were separated and their fresh weight was measured. For dry weight, the root and shoot were dried in oven at $70^{\circ} \mathrm{C}$ until the constant weight was recorded.

\section{Chemical analysis}

For nanoparticles analysis, plants were harvested after 12 days, washed with distilled water and oven dried at $70^{\circ} \mathrm{C}$. The dry shoot samples of the plants were digested with $5 \mathrm{~mL}$ $70 \% \mathrm{HNO}_{3}$ and $1 \mathrm{~mL}$ perchloric acid for $3 \mathrm{~h}$ at $130^{\circ} \mathrm{C}$. The distilled water was added for suitable dilution. The concentrations of nanoparticles were determined by the inductively coupled plasma/atomic emission spectroscopy (ICP-AES) (Model: Ultima; Horiba Jobin-Yvon Co., Longjumeau, France).

\section{Results and Discussion}

\section{Growth curve of mung plant}

Figure 1 shows the growth of control and nanoparticle Foliar sprayed mung seedlings in Hogland solution. To compare the growth in different parts of the plant, morphological characteristics like shoot length, root numbers and root length were observed for 12 days (Figure 2). It was observed that the mass accumulation was paralleled by morphological adjustments such as increased shoot length, number of roots and root length in presence of nanoparticles compared to the control.

Since the mode of nanoparticle treatment was through Foliar spraying on leaves, shoot growth as an indicator towards the effect of nanoparticles treatment was quantified. The comparative growth of control and nanoparticles treated mung plants in terms of shoot length $v s$ number of days is shown in Figure 3. The plants were harvested after 12 days and the average shoot length of control and nanoparticle treated mung plants was determined, as shown in Figure 4. From Figures 3 and 4 it is evident how the rate of plant growth as determined from their shoot length was
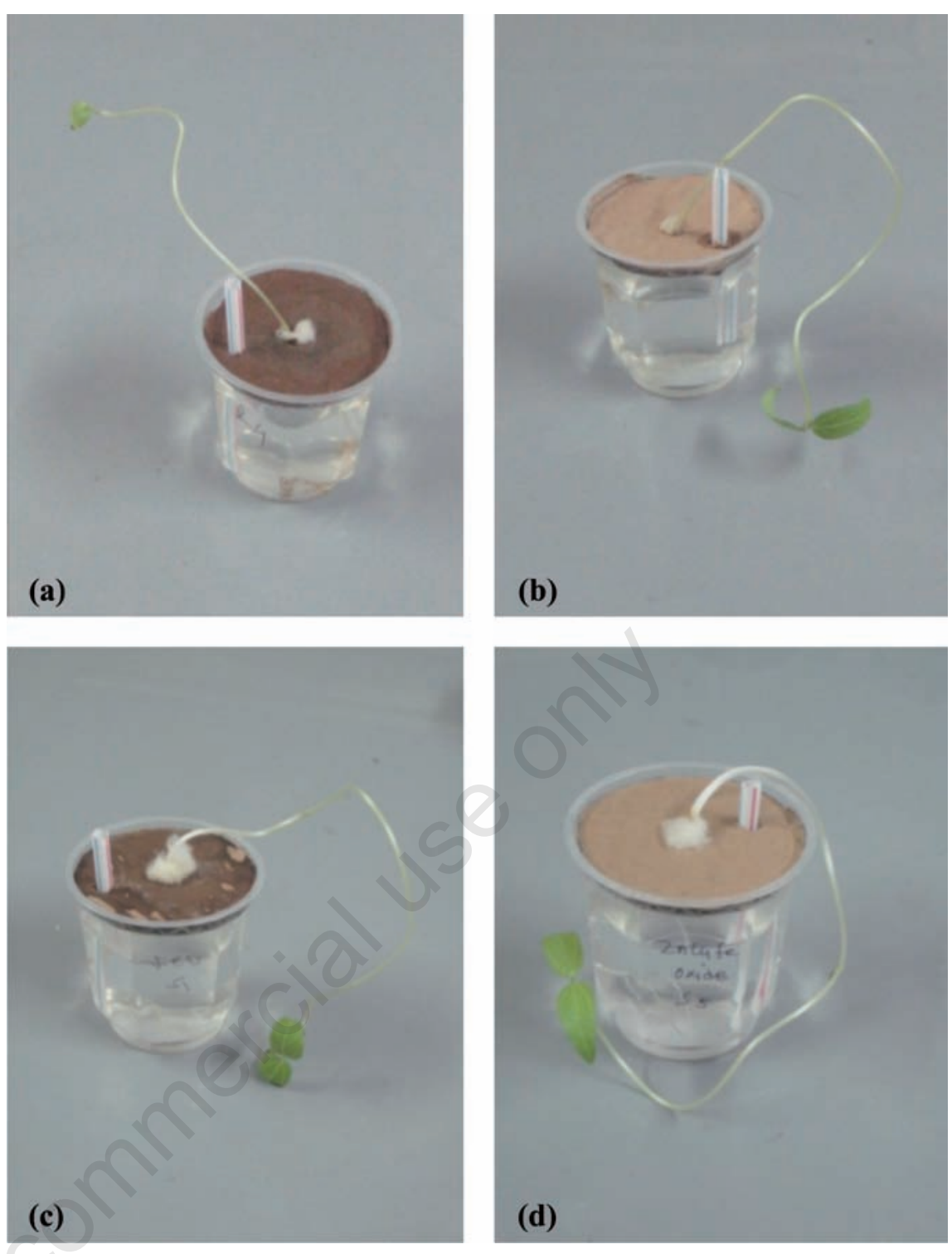

Figure 1. Growth of mung seedlings in Hogland solution followed by Foliar spraying of nano-suspension under control condition for 12 days: (a) control, (b) $20 \mathrm{ppm}$ nano-ZnO, (c) $50 \mathrm{ppm}$ nano-FeO, and (d) $50 \mathrm{ppm}$ nano-ZnCuFe Oxide.
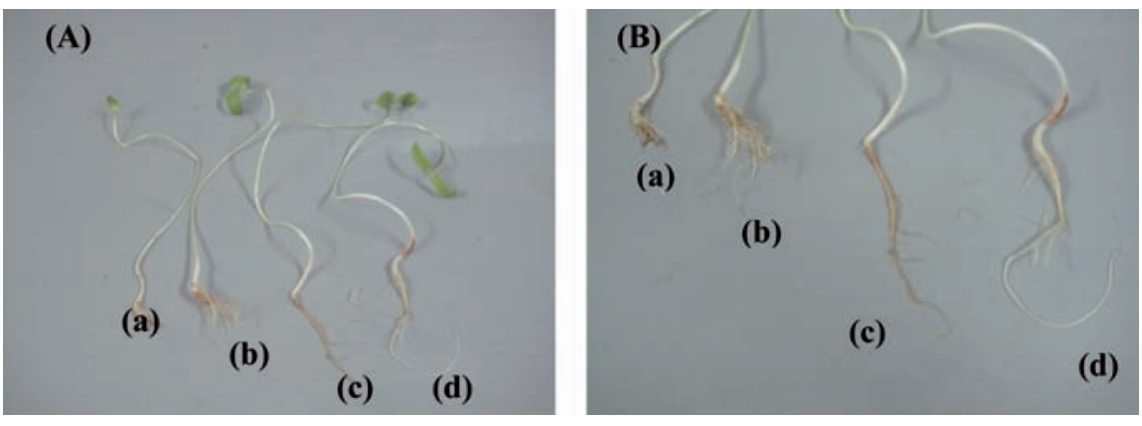

Figure 2. (A) shoot growth and (B) root growth of mung seedlings after foliar spray of different nanoparticles under control condition for 12 days: (a) control, (b) 20 ppm nano$\mathrm{ZnO}$, (c) 50 ppm nano-FeO, and (d) 50 ppm nano-ZnCuFe Oxide. 
maximum for $\mathrm{ZnFeCu}$-oxide nanoparticles treatment, followed by nano-FeO and nano$\mathrm{Zn0}$, as compared to the control that had the lowest growth rate. In particular, the $\mathrm{ZnFeCu}$ oxide nanoparticles treated plant showed $15.71 \%$ increase in shoot length, while the plants treated with $\mathrm{FeO}$ nanoparticles showed $10.25 \%$ increase, and $\mathrm{ZnO}$ nanoparticles showed $6.47 \%$ increase with respect to control.

\section{Effect of nanoparticles suspension on biomass}

The graph of root and shoot wet and dry biomass estimated with respect to the concentration of nanoparticles for mung plants after 12 days is shown in Figure 5. Root and shoot biomass productions were found to be in accordance with the root and shoot length for the corresponding nanoparticle treatment.

\section{Wet biomass}

Nano-Zn0 (20 ppm) sprayed plants showed a $31.79 \%$ increase in root biomass and a $38.36 \%$ increase in shoot biomass; nano-Fe0 (50 ppm) sprayed plants showed a $30.15 \%$ increase in root biomass and a 50.44\% increase in shoot biomass; and nano- $\mathrm{ZnFeCu}$ 0xide (50 ppm) sprayed plants showed a $58.79 \%$ increase in root biomass and a $85.76 \%$ increase in shoot biomass over the control.

\section{Dry biomass}

Nano-Zn0 (20 ppm) sprayed plants showed a $39.59 \%$ increase in root biomass and a $44.09 \%$ increase in shoot biomass; nano-FeO (50 ppm) sprayed plants showed a $68.16 \%$ increase in root biomass and a $47.61 \%$ increase in shoot biomass; and nano- $\mathrm{ZnFeCu}$ 0xide (50 ppm) sprayed plants showed a $42.45 \%$ increase in root biomass and a $83.92 \%$ increase in shoot biomass over the control.

\section{Elemental determination in mung shoot by inductively coupled plasma/atomic emission spectroscopy}

Table 1 shows the concentration of zinc $(\mathrm{Zn})$, iron $(\mathrm{Fe})$ and copper $(\mathrm{Cu})$ content in the mung shoot. The three nutrient elements ( $\mathrm{Zn}$, $\mathrm{Fe}$ and $\mathrm{Cu}$ ) found in reference plants are absorbed from Hoagland solution. However, for nano-Zn0 (20 ppm) sprayed plants, $6.59 \mathrm{mg} / \mathrm{L}$ of $\mathrm{Zn}$ concentration was observed; for nano$\mathrm{Fe} 0$ (50 ppm) sprayed plants, $11.49 \mathrm{mg} / \mathrm{L}$ of Fe concentration was observed; and for nanoZnFeCu-Oxide (50 ppm) sprayed plants, 0.54 $\mathrm{mg} / \mathrm{L}$ of $\mathrm{Zn}, 4.23 \mathrm{mg} / \mathrm{L}$ of Fe and $6.66 \mathrm{mg} / \mathrm{L} \mathrm{of} \mathrm{Cu}$ concentrations were observed. The presence of these elements found in plants sprayed with nanoparticles suspensions which were kept in Hoagland solution suggests that the sprayed nanoparticles may got absorbed through the

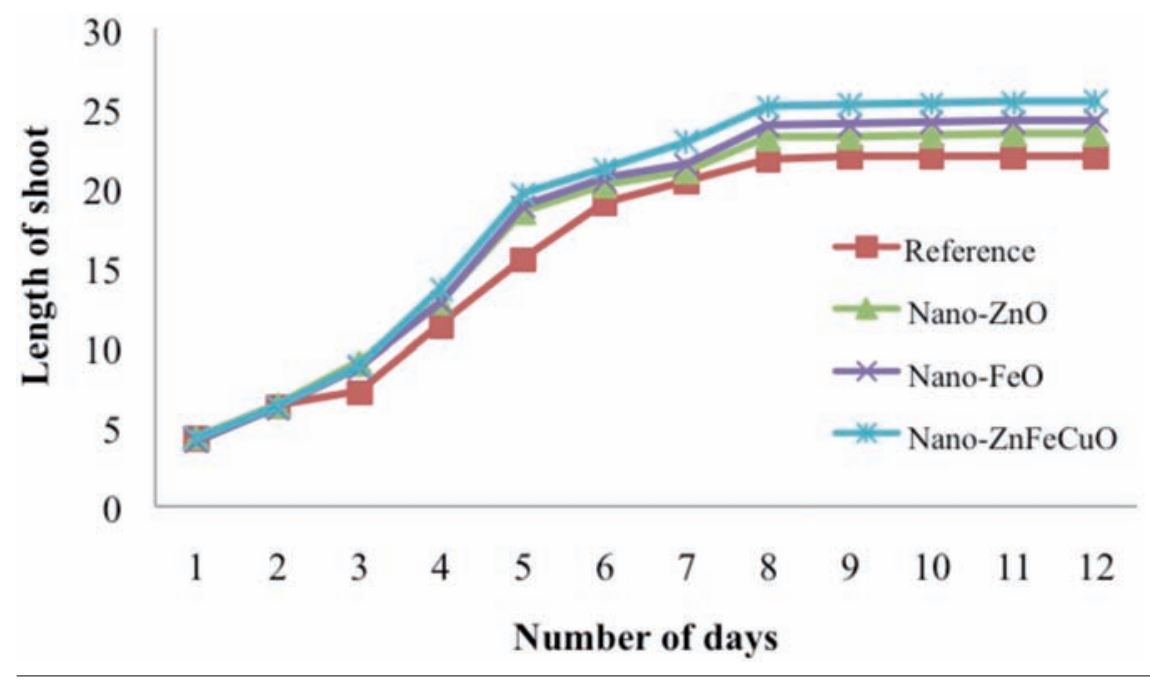

Figure 3. Comparison between the shoot growth of mung plant treated with various nanoparticles. Values associated with each data point represent the average shoot length.

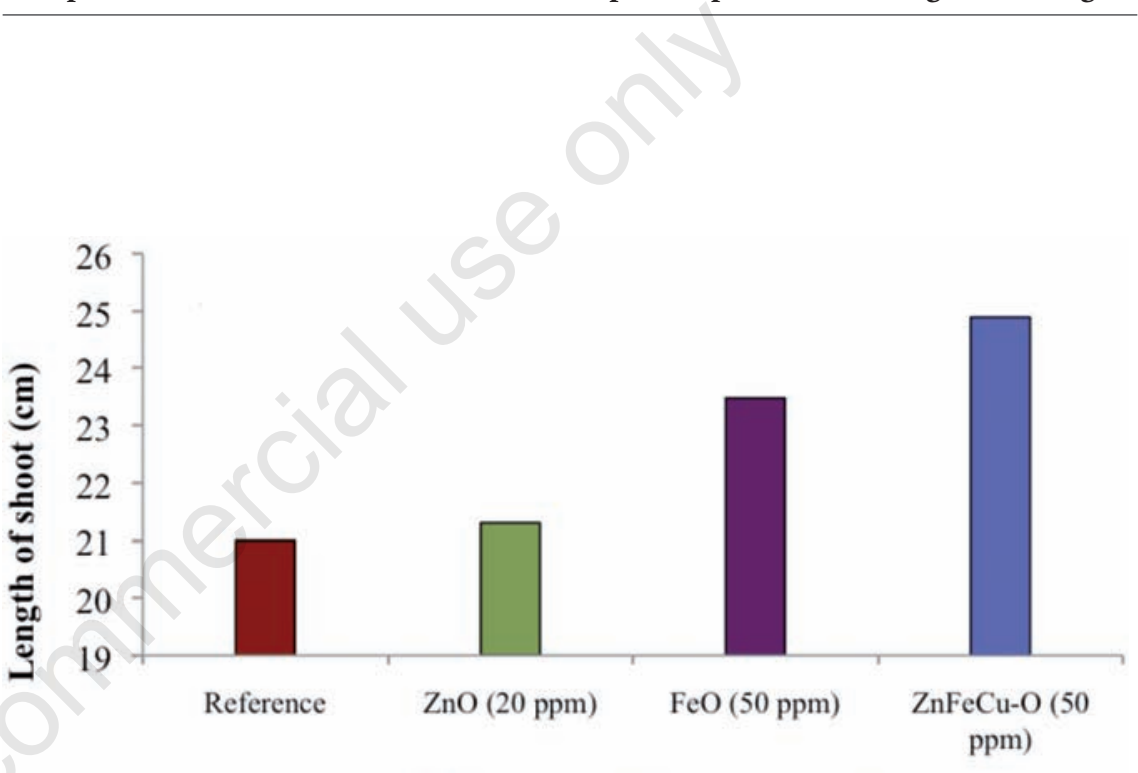

\section{Applied nanoparticles concentration}

Figure 4. Average shoot length of mung plant for control and nanoparticles treated after 12 days of harvest.

Table 1. Concentration of zinc, iron, and copper elements in mung shoot determined by inductive coupled plasma/atomic emission spectroscopy.

\begin{tabular}{lcc}
$\begin{array}{l}\text { Applied concentration } \\
\text { of nanoparticles suspension }\end{array}$ & $\begin{array}{c}\text { Elements } \\
\text { detected }\end{array}$ & $\begin{array}{c}\text { Concentration } \\
\text { Reference (without nanoparticles) }\end{array}$ \\
& $\mathrm{Zn}$ & 0.25 \\
& $\mathrm{Fe}$ & 5.32 \\
Nano-ZnO (20 ppm) & $\mathrm{Cu}$ & 5.12 \\
Nano-FeO (50 ppm) & $\mathrm{Zn}$ & 6.59 \\
Nano-ZnFeCu-oxide $(50 \mathrm{ppm})$ & $\mathrm{Fe}$ & 11.49 \\
& $\mathrm{Zn}$ & 0.54 \\
& $\mathrm{Fe}$ & 4.23 \\
& $\mathrm{Cu}$ & 6.66 \\
\hline
\end{tabular}

ICP-AES, inductive coupled plasma/atomic emission spectroscopy; Zn, zinc; Fe, iron; Cu, copper. 


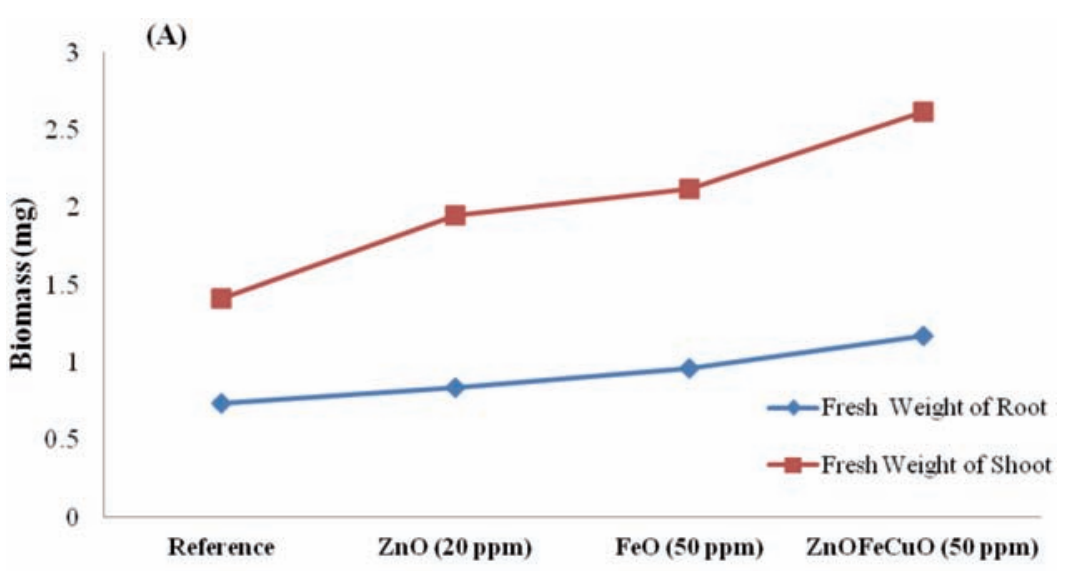

Applied nanoparticles concentration

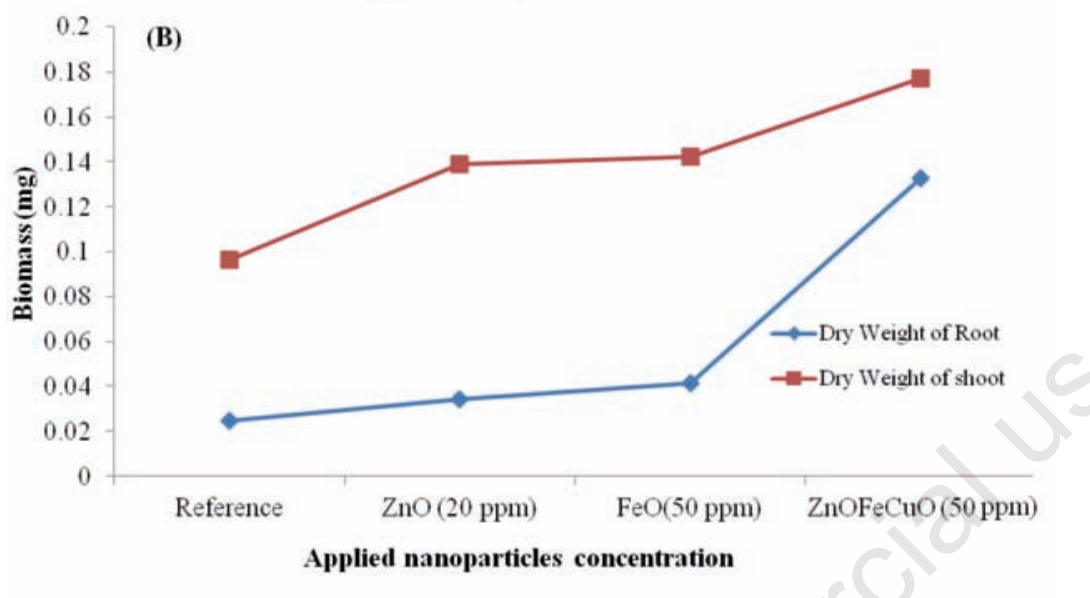

Figure 5. Wet (A) and dry (B) biomass of root and shoot of mung plant.

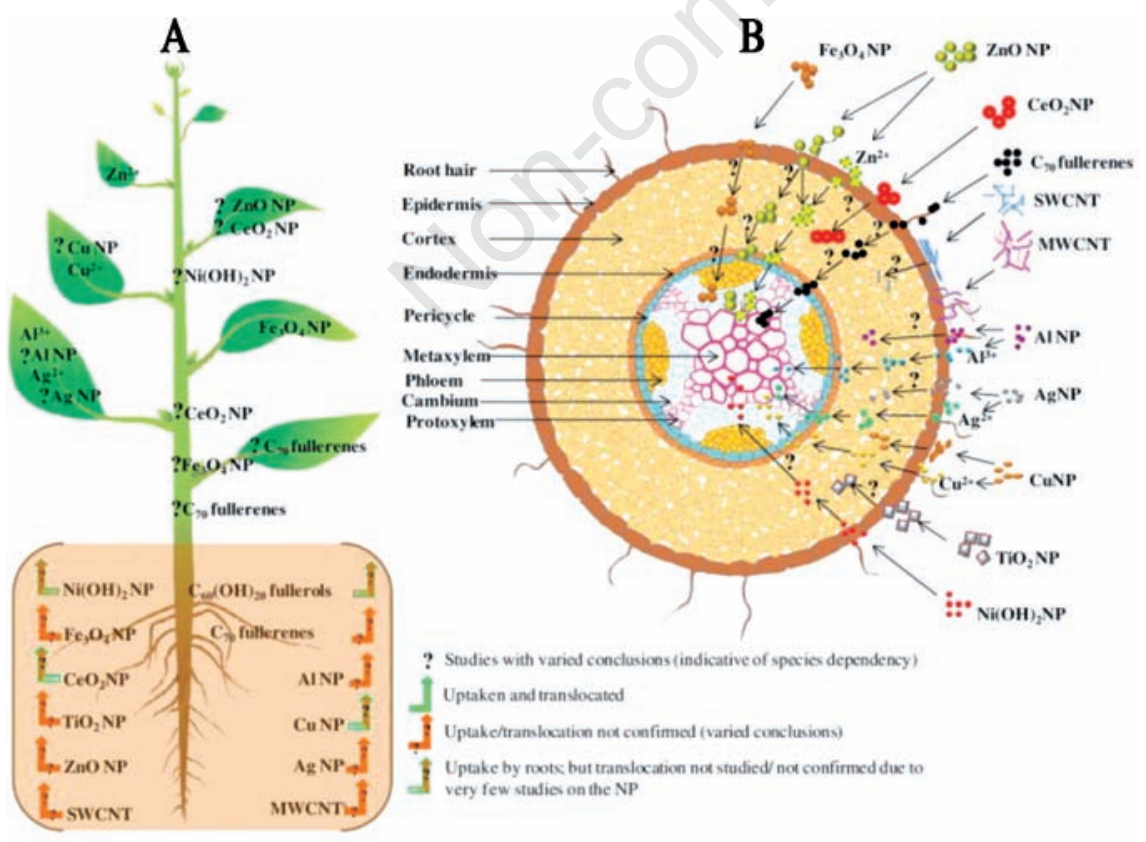

Figure 6. Uptake, translocation and biotransformation pathway of various nanoparticles in a plant system. A, plant showing the selective uptake and translocation of nanoparticles (NPs). B, transverse cross section of the root absorption zone showing the differential nanoparticles interaction on exposure. ${ }^{1}$ stomata of leaves and translocated in plant. The selective uptake, biotransformation, and translocation of various nanoparticles by a model plant have been schematically represented in Figure $6 .^{1}$ Nanoparticles have high reactivity because of more specific surface area, more density of reactive areas, or increased reactivity of these areas on the particle surfaces. These features in nano-scale simplify their absorption in plants.

This also explains the increase in biomass accumulation by the mung plants. Each nutrient element under study ( $\mathrm{Zn}, \mathrm{Fe}$ and $\mathrm{Cu}$ ) plays a vital role in photosynthesis. For example, Zn plays an important role in many biochemical reactions within the plants like formation of chlorophyll and carbohydrates. ${ }^{16,17}$ Iron is one of the essential elements for plant growth and plays an important role in photosynthetic reactions. Iron activates several enzymes and contributes in RNA synthesis and improves the performance of photosystems. ${ }^{18-20}$ Similarly, trace amount of $\mathrm{Cu}$ is a component of regulatory proteins, participates in electron transport in photosynthesis and respiratory chains. ${ }^{1}$

\section{Conclusions}

The nanoparticle suspensions of $\mathrm{ZnO}$, FeO and $\mathrm{ZnFeCu}$-oxide were able to affect the development and growth processes of the mung (Vigna radiata) plant by foliar spray. Pronounced effect on increasing in root and shoot length as well as accumulation of biomass was recorded for nanoparticle treated plant as compared to the reference. Among the different nanoparticle suspensions, the maximum effect was found at $50 \mathrm{ppm} \mathrm{ZnFeCu}$-oxide followed by $50 \mathrm{ppm} \mathrm{Fe} 0$ and least for $20 \mathrm{ppm}$ $\mathrm{ZnO}$ depending on their chemical composition, size and surface energy. These findings show that the use of nanoparticle suspensions by foliar spray for directed delivery of substances into plant cells is a feasible application.

\section{References}

1. Rico CM, Majumdar S, Duarte-Gardea M, et al. Interaction of nanoparticles with edible plants and their possible implications in the food chain. J Agr Food Chem 2011; 59:3485-98.

2. Ruffini CM, Cremonini R. Nanoparticles and higher plants. Caryologia 2009;62:161-5.

3. Nair R, Varghese SH, Nair BG, et al. Nanoparticulate material delivery to plants. Plant Sci 2010;179:154-63.

4. Mahajan P, Dhoke SK, Khanna AS. Effect of Nano-ZnO particle suspension on growth of mung (Vigna radiata) and Gram 
(Cicer arietinum) seedlings using plant agar method. J Nanotechnol 2011;ID 696535:1-7. Available from: http://yghh.ca/ news/effect-nano-zno-particle-suspension-growth-mung-vigna-radiata-andgram-cicer-arietinum

5. Park HJ, Kim SH, Kim HJ, Choi SH. A new composition of nano sized silica-silver for control of various plant diseases. Plant Pathol 2007;22:295-302.

6. Galbraith DW. Nanobiotechnology: silica breaks through in plants. Nat Nanotechnol 2007;2:272-3.

7. Gonzalez-Melendi P, Fernandez-Pacheco R, Coronado MJ. Nanoparticles as smart treatment-delivery systems in plants: assessment of different techniques of microscopy for their visualization in plant tissues. Ann Bot-London 2008;101:187-95.

8. Yang L, Watts DJ. Particle surface characteristics may play an important role in phytotoxicity of alumina nanoparticles. Toxicol Lett 2005;158:122-32.

9. Lee WM, An YJ, Yoon H, Kweon HS. Toxicity and bioavailability of copper nanoparticles to the terrestrial plants mung bean (Phaseolus radiatus) and Wheat (Triticum aestivum): plant agar test for water-insoluble nanoparticles. Environ Toxicol Chem 2008;27:1915-21.

10. Lin D, Xing B. Phytotoxicity of nanoparticles: inhibition of seed germination and root growth. Environ Pollut 2007;150: 243-50.

11. Lu CM, Zhang CY, Wen JQ, et al. Research on the effect of nanometer materials on germination and growth enhancement of glycine max and its mechanism. Soybean Sci 2002;21:68-172.

12. Hong F, Zhou J, Liu C. Effect of nano-Ti02 on photochemical reaction of chloroplasts of spinach. Biol Trace Elem Res 2005;105: 269-79.

13. Hong F, Yang F, Liu C. Influences of nanoTiO2 on the chloroplast aging of spinach under light. Biol Trace Elem Res 2005;104: 249-60.

14. Yang F, Hong F, You W. Influences of nanoanatase TiO2 on the nitrogen metabolism of growing spinach. Biol Trace Elem Res 2006;110:179-90.

15. Canas JE, Long M, Nations S. Effects of functionalized and non-functionalized single-walled carbon nanotubes on root elongation of select crop species. Environ Toxicol Chem 2008;27:1922-31.

16. Corredor E, Testillano PS, Coronado MJ, et al. Nanoparticle penetration and transport in living pumpkin plants: in situ subcellular identification. BMC Plant Biol 2009;9:45-54.

17. Gianquinto G, Azmi AR, Tola LD, et al. Interaction effects of phosphorus and zinc on photosynthesis, growth and yield of dwarf bean grown in two environments. Plant Soil 2000;220:219-28.

18. Sheykhbaglou R, Sedghi M, Mehdi TS, Rauf SS. Effects of nano-iron oxide particles on agronomic traits of soybean. Not Sci Biol 2010;2:112-3.

19. Liu XM, Zhang FD, Zhang SQ, et al. Effects of nano-ferric oxide on the growth and nutrients absorption of peanut. Plant Nutr Fert Sci 2010;11:14-8.

20. Eddings JL, Brown AL. Absorption and translocation of foliar-applied iron. Plant Physiol 1967;42:15-9. 